NASA Technical Memorandum 89925

AIAA-87-9355

\title{
EMC and Power Quality Standards for $20-\mathrm{kHz}$ Power Distribution
}

\author{
(NASA-TH-89925) EMC AND PCHEE CUALITY \\ STANDABDS FOR 20-KHZ ECHEB DISTEIEOTION \\ (NASA) $8 \mathrm{p}$ AVAII: NIIS HC $A 02 / B P$ AOI \\ CSCL 09C \\ N87-22004 \\ Unclas \\ H1/20 0074228
}

Irving G. Hansen

Lewis Research Center

Cleveland, Ohio

Prepared for the

22nd Intersociety Energy Conversion Engineering Conference cosponsored by the AIAA, ANS, ASME, SAE, IEEE, ACS, and AIChE Philadelphia, Pennsylvania, August 10-14, 1987

\section{Nusn}


Irving G. Hansen

National Aeronautics and Space Administration

Lewis Research Center

Clevel and, Ohio 44135

\section{Abstract}

The Space Station Power Distribution System has been baselined as a sinusoidal single phase, 440 VRMS, $20 \mathrm{kHz}$ system. This system has certain unique characteristics that directly affect its application. In particular existing systematic description and control documents were modified to reflect the higher operating frequency.

This paper will discuss amendments made on Mil STO 704 ("Electrical Power Characteristics"), and Mil STD 461-B ("Electromagnetic Emission and Susceptibility Requirements for the Control of Electromagnetic Interference").

In some cases these amendments reflect changes of several order of magnitude. This paper will discuss some of the implications and impacts of these changes.

\section{Background}

The $20 \mathrm{kHz}$ Space Station Power Management and Distribution (PMAD) System has several unique characteristics which directly enhance both user power quality, and electromagnetic emission control. In order to define and codify these characteristics existing MIL Specifications were amended to represent the newer conditions. Two such specif ications containing modifications are: "Space Station Electrical Power Standard" JSC 30482 (MILSTD-704 Amended) and "Space Station Electromagnetic Emission and Susceptibility Requirements for EMC" JSC 30237 (MIL-STD-461-B Amended).

\section{System Characteristics}

The Space Station Power System delivers power by means of a $20 \mathrm{kHz}$, single phase, sinusoidal, high voltage. Although a distribution frequency of $20 \mathrm{kHz}$ appears to be high when first encountered, the fact that a regulated, low distortion, sinewave is involved greatly limits the wide frequency noise spectrum comonly associated with switched mode power converters.

As the voltage is regulated variations in delivered power cause an amplitude modulation of the $20 \mathrm{kHz}$ current waveform. The harmonics represented by modulation of the current waveform will be contained in sidebands clustered about the $20 \mathrm{kHz}$ "carrier." As an example a current waveform supplying a $400 \mathrm{~Hz}$ single phase load is illustrated in Fig. 1. As power is delivered by a sinusoidal wave and even the most severe current distortions involve only the first two odd harmonics, essentially the total noise spectrum will be contained in bands of frequencies occurring at multiples of the carrier and two others of reduced amplitude clustered about the third, $(60 \mathrm{kHz})$ and the fifth $(100 \mathrm{kHz})$ harmonics. This limited source energy spectrum has two advantages: no appreciable system energy is transmitted at the frequencies of most interest to the science community $(0$ to
$10 \mathrm{kHz}$ ), and the energy actually transmitted is confined to a few, well defined frequency bands. 1,2

At the load end of the system lower frequencies, if required, will be synthesized from the $20 \mathrm{kHz}$ carrier. The synthes is scheme used will allow the low frequency amplitude, and waveform to be controlled independently. Independent control to these two variables again limits the energy spectrum, which in turn results in a inherently "clean" system. A study of low frequency synthesis was performed at the University of Wisconsin at Madison. 3 Some results of that effort are shown in Fig. 7. Shown are a computer simulation of one phase of a three phase $400 \mathrm{~Hz}$ converter. The waveform taken from an operating breadboard, and a spectrum analysis performed upon the breadboard output.

\section{Power Feeder Cables}

The design of the feeder cables has a direct impact on both the power quality, and the systems ability to avoid susceptibility (cross talk). To meet the simultaneous requirements of High Efficiency, Low Cross Talk, and low external radiation a three conductor "flat" cable was developed (Fig. 3). This cable is essentially a double sided strip line with a very low characteristics impedance. The equivalent circuit for this cable would be a low pass filter section with a low inductance, relative high capacitance, and a corner frequency above $100 \mathrm{kHz}$. The cable/system is designed to provide power with $(+2.5$ percent $)$ total regulation/cross talk. As a result of this low impedance, this system is remarkably tolerant of current distortion. To illustrate this point a $25 \mathrm{KW}$ source driving $50 \mathrm{~m}$ of flat transmission line was loaded with an intentionally distorted current waveform (Fig. 4). As shown, in a third harmonic current distortion of over 40 percent resulted in a third harmonic voltage distortion of less than 4 percent (Fig. 5). The actual levels of total current distortion allowed on the space station will be controlled to levels much less than those used in the experiment.

\section{Space Station Electrical Power Standard JSC 30482 (MIL-STO-704 Amended)}

As indicated by the title the power standard is MIL-STO-704 modified to reflect the higher operating frequency. The normal operation steady state characteristics are shown in Figure 7 . One significant difference in the amended standard is the expansion of the definition of abnormal operation to comprise three classes of failure in order to accommodate the redundancy of the Space Station Power System. Another amendment is the reduction of transient voltage envelope to a maximum of +10 percent, (was +56 to -30 percent) and reducing the envelope duration to $1 \mathrm{msec}$ (was $80 \mathrm{msec}$ ). These amendments basically reflect the improvements achieved by electronic power conversion as opposed to rotating machine response. 
For the Space Station the EMC Requirements are specified by JSC-30237 "Space Station Electromagnetic Emission and Susceptibility Requirements for EMC." (Mil-STO 461-B Amended).

These specifications have been amended to pro$v$ ide a lower radiated emission environment for the science payloads located on the upper and lower boom. For example, RE 02 Broadband limit allows an additional 32 ob reduction in the scientific areas.

At present it is also intended to apply different level specifications to individual equipment and to integrated systems. As an example magnetic radiation would be measured at $7 \mathrm{~cm}$ (Mil-STD 462) at the equipment level, but the measurement would be made at $1 \mathrm{~m}$ on the integrated system. This procedure will allow greater than $20 \mathrm{Db}$ additional margin for system effects.

Other than these modifications the external (emission) specifications of Mil STD 461-B will remain unchanged.

Viewing the Power Distribution System as an end-to-end entity from the source to the user interface conducted interferences, not effecting systematics, are of concern only to the extent that they involve radiation. To the extent that the total system has not been either designed or evaluated the conducted interference have largely represented power system requirements and capabilities.

\section{Conducted Susceptibility Test CSOI-8}

In the High Frequency Distribution System conducted susceptibility addresses the response of attached equipment to distortion of the distribution voltage waveform. CSOl-B requires equipment to operate under the conditions defined by JSC 30482 (power quality). This basically defines a response to harmonic distortion under normal and abnormal conditions.

For $20 \mathrm{kHz}$ AC power both the susceptibility and conducted interference specifications will be referenced to harmonic distortion of the supply voltage and the supply current.

\section{Remaining to be Specified}

1. An improved flat cable constructed in a more dimensionally stable manner will further reduce the magnetic field radiated at $20 \mathrm{kHz}$.

2. A determination of the module distribution architecture and bus impedance must be made before final conducted interference specifications may be created to define user interfaces.

3. Modeling must be developed to predict systematic effects and to intelligently grant specification wavers.

\section{References}

1. Mildice, J., "AC Power System Test Bed," NASA CR-175068, 1986.

2. Hansen, I.G. and Wolff, F.J., "20 Kilohertz Space Station Power System," NASA TM-88801, 1986.

3. Lipo, T.A. and Sood, P.K., "Study of the Generator/Motor Operation' of Induction Machines in a High Frequency Link Space Power System," NASA CR-179600, 1987. 


\section{CROBVAL PAOE IS \\ OF POOR QUAUTY}

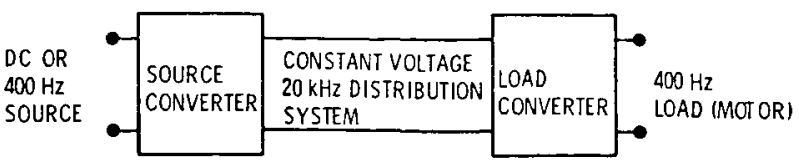

- the distribution Voltage Remains constant

- the distribution CURRENT WILL be $20 \mathrm{kHz}$ WITH a $400 \mathrm{~Hz}$ aMPLITUOE VARIATION
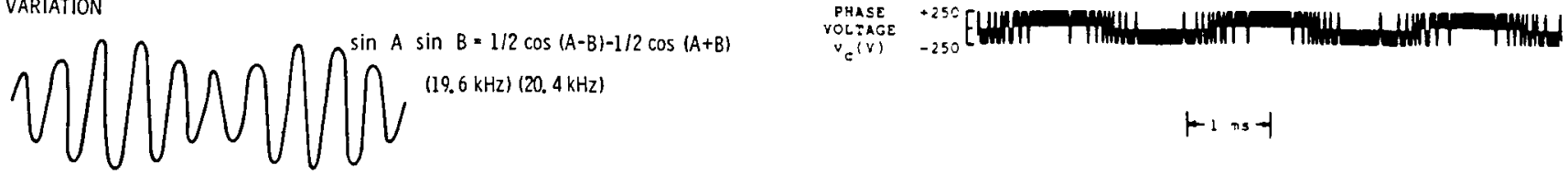

$$
1-1, n-1
$$

- THE ENERGY SPECTRUM OF THE DISTRIBUTION SYSTEM CONTAINS ONLY 19.6 kHz, 20.0 kHz AND $20.4 \mathrm{kHz}$

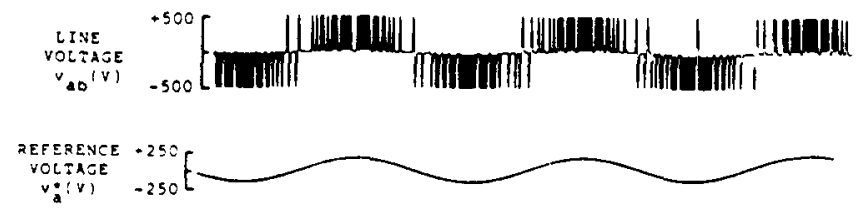

FIGURE 1 CURRENT MODULATION

FIGURE (Ib) COMPUTER SIMULATION OF LOW FREQUENCY SYNTHESIS (2a) (UNIVERSITY OF WISCONSIN)

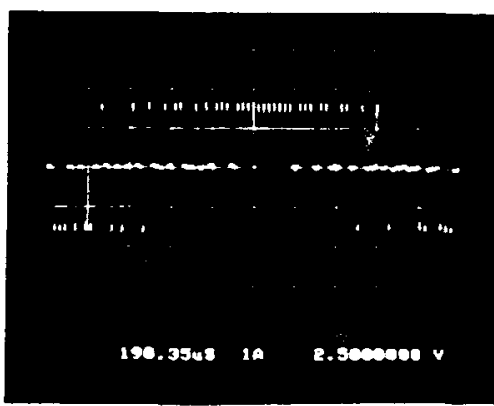

FIGURE (2b)

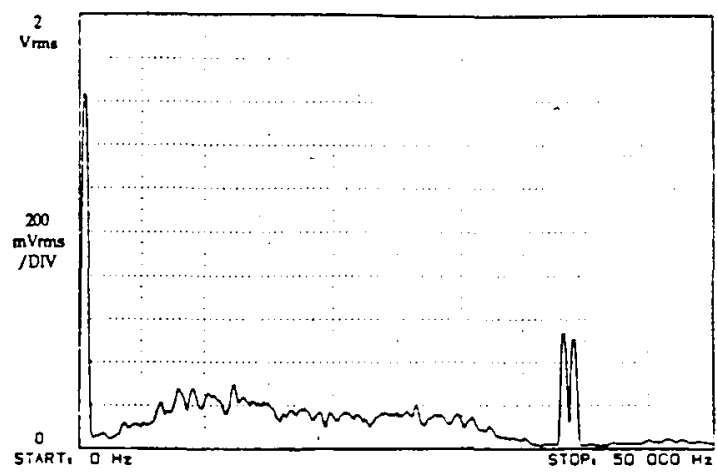

FIGURE (2C)

Output of breadboard synthesizer (University of Wisconsin)

Spectrum of breadboard

Synthesizer (University of

Wisconsin) (1st sideband Set)

FIGURE 2 


\section{CREMTAL PAOE IS OF POOR QUAUTY}

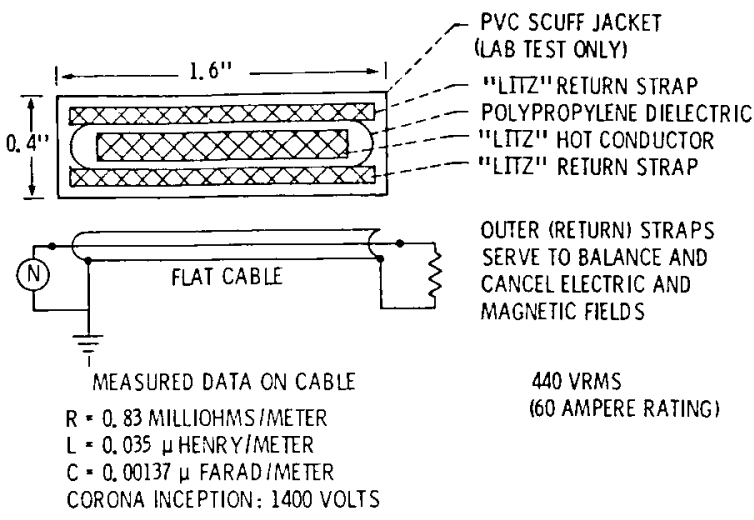

FIGURE 3 FLAT CABLE
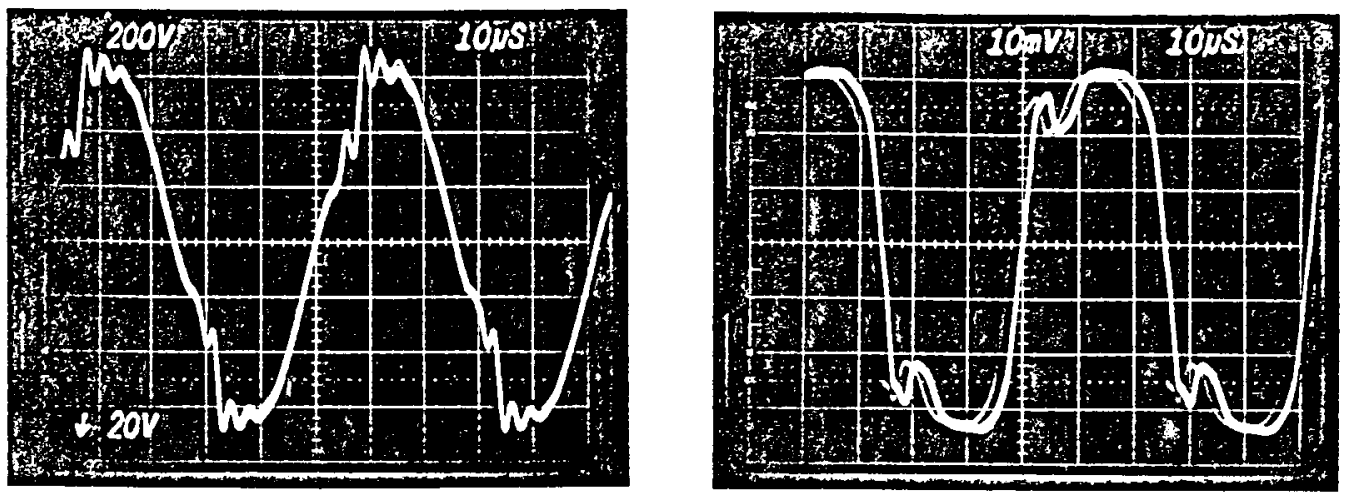

FIGURE 4 CROSS TALK AT RECEIVER WITH NO INPUT FILTER

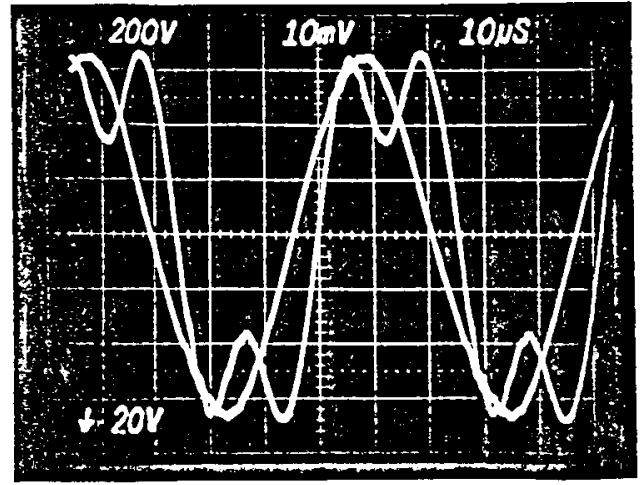

FIGURE $4-a$

CROSS TALK WITH FILTERS 
RECEIVING AND BUS CURRENT

\begin{tabular}{|c|r|r|}
\hline$f(\mathrm{kHz})$ & \multicolumn{1}{|c|}{$\mathrm{dBA}(\mathrm{lr})$} & \multicolumn{1}{|c|}{$\% \mathrm{i} / 1 \mathrm{r}$} \\
\hline 0 & -88.00 & $0.00 \%$ \\
20 & 0.00 & $100.00 \%$ \\
40 & -51.60 & $0.26 \%$ \\
60 & -7.70 & $41.21 \%$ \\
80 & -47.00 & $0.45 \%$ \\
100 & -29.30 & $3.43 \%$ \\
120 & -64.70 & $0.06 \%$ \\
140 & -39.80 & $1.02 \%$ \\
160 & -64.20 & $0.06 \%$ \\
180 & -46.40 & $0.48 \%$ \\
& & \\
\hline
\end{tabular}

RECEIVING END BUS VOLTAGE

\begin{tabular}{|c|c|c|}
\hline$f(\mathrm{kHz})$ & $\mathrm{dBV}(\mathrm{Vr})$ & \multicolumn{1}{|c|}{$\% / \mathrm{Vr}$} \\
\hline 0 & -100.30 & $0.00 \%$ \\
20 & 0.00 & $100.00 \%$ \\
40 & -50.60 & $0.30 \%$ \\
60 & -27.80 & $4.07 \%$ \\
80 & -45.70 & $0.52 \%$ \\
100 & -29.40 & $3.39 \%$ \\
120 & -60.90 & $0.09 \%$ \\
140 & -39.70 & $1.04 \%$ \\
160 & -59.20 & $0.11 \%$ \\
180 & -46.70 & $0.46 \%$ \\
\hline
\end{tabular}

FIGURE 5 VOLTAGE AND CURRENT DISTORTION MEASUREMENTS

AC NORMAL OPERATION STEADY STATE CHARACTERISTICS

From JSC 30482 Mil STD 704 Amended

\begin{tabular}{ll}
\hline \multicolumn{1}{c}{ CHARACTERISTICS } & \multicolumn{1}{c}{ LIMITS } \\
\hline Voltage & 429 to 451 volts \\
Waveform distortion factor & 0.03 maximum \\
Waveform distortion spectrum & Figure 1 \\
OC component & +0.10 to -0.10 volts \\
Frequency & $20 \mathrm{kHz} \pm 0.5 \%$ \\
\hline
\end{tabular}

FIGURE 6

STEADY STATE 


\section{AC ABNORMAL OPERATION CHARACTERISTICS}

CHARACTERISTIC

POWER OROP

OUT

WAVE FORM DISTORTION

FACTOR

WAVE FORM SPECTRUM

FREQUENCY DEVIATION

VOLTAGE

\author{
FAILURE LEVEL \\ (See Note (1)
}

ONE

Two

ONE

THO

ONE

TWO

ONE

TWO

ONE

TWO
LIMITS

TBD MICROSECONDS

(50 TYPICALLY

TBD MILLISECONDS

(500 TYPICALLY)

NO CHANGE

TBO

NO CHANGE

TBD

NO CHANGE

TBD

NO CHANGE

NOTE 1. The electrical power system is multiply redundant and reconfigurabie. The power standards which apply to any particular load is a function of the load priority and the level of the systen failure. For purpose of this classification a level one failure involves the loss of one of several power feeder paths. Level two failures represent the loss of an additional feeder, or an energy source.

Level two failure accommodation involves failure analysis, load shedding, and system reconfiguration. Safe Haven operation concerns level three failures involving major portions of the power system.

FIGURE 7 


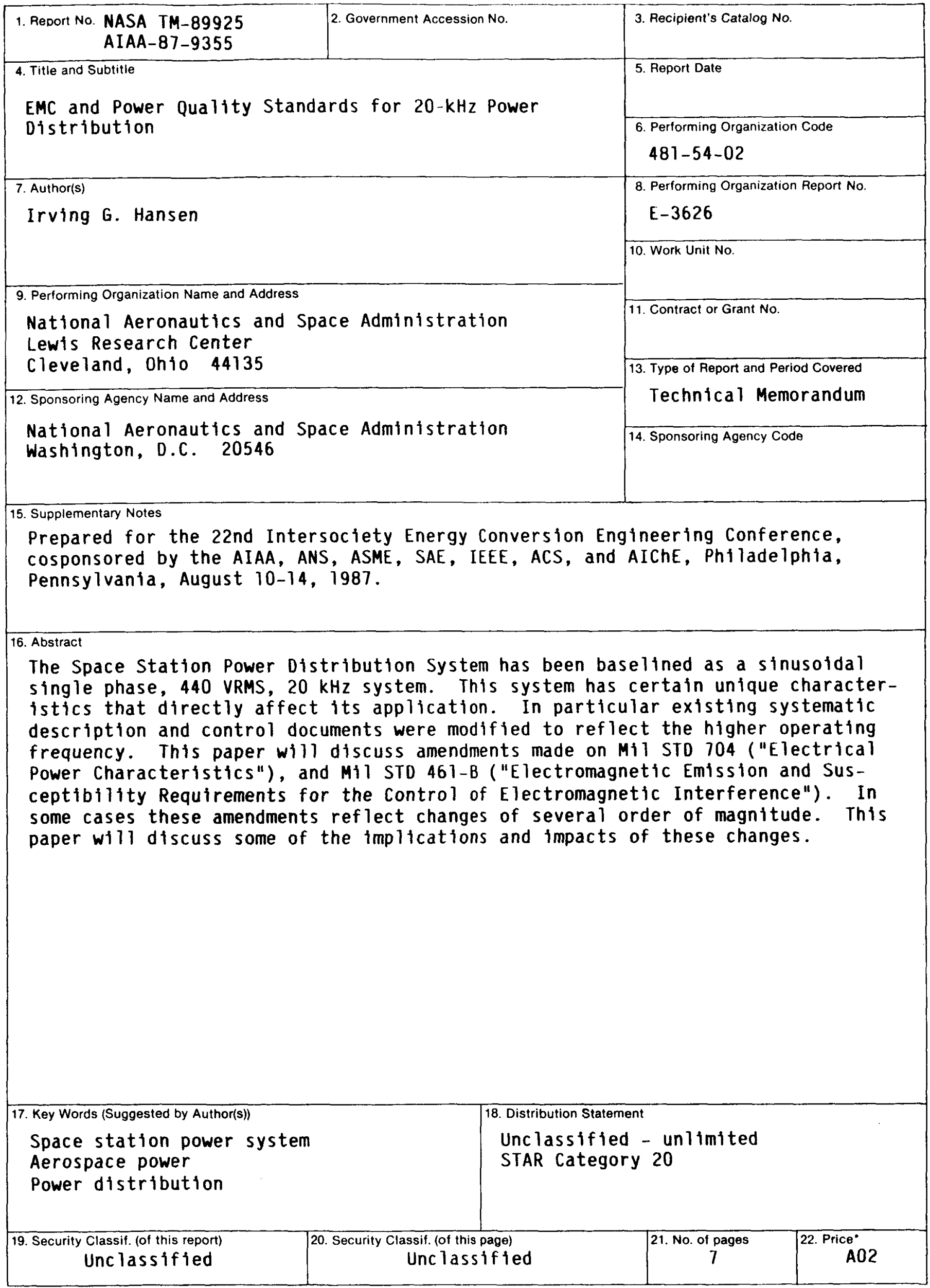

"For sale by the National Technical Information Service, Springfield, Virginia 22161 